\title{
Home-Based Rehabilitation With Telemonitoring Guidance for Patients With Coronary Artery Disease (Short-Term Results of the TRiCH Study): Randomized Controlled Trial
}

Andrea Avila ${ }^{1}$, MD, MSc; Jomme Claes², BSc, MSc; Kaatje Goetschalckx ${ }^{3}$, MD; Roselien Buys ${ }^{2}$, BSc, MSc, PhD; May Azzawi ${ }^{4}, \mathrm{PhD}$; Luc Vanhees ${ }^{1}, \mathrm{PhD}$; Véronique Cornelissen ${ }^{1}, \mathrm{PhD}$

${ }^{1}$ Department of Rehabilitation Science, KU Leuven, Leuven, Belgium

${ }^{2}$ Department of Cardiovascular Sciences, KU Leuven, Leuven, Belgium

${ }^{3}$ Department of Cardiology, University Hospital Leuven, Leuven, Belgium

${ }^{4}$ Cardiovascular Research Group, School of Healthcare Science, Manchester Metropolitan University, Manchester, United Kingdom

\section{Corresponding Author:}

Véronique Cornelissen, $\mathrm{PhD}$

Department of Rehabilitation Science

KU Leuven

O\&N IV Herestraat 49 - Bus 1510

Leuven, 3000

Belgium

Phone: 3216329152

Email: veronique.cornelissen@kuleuven.be

\section{Abstract}

Background: Cardiac rehabilitation (CR) is an essential part of contemporary coronary heart disease management. However, patients exiting a center-based $\mathrm{CR}$ program have difficulty retaining its benefits.

Objective: We aimed to evaluate the added benefit of a home-based CR program with telemonitoring guidance on physical fitness in patients with coronary artery disease (CAD) completing a phase II ambulatory CR program and to compare the effectiveness of this program in a prolonged center-based CR intervention by means of a randomized controlled trial.

Methods: Between February 2014 and August 2016, 90 CAD patients (unblinded, mean age 61.2 years, SD 7.6; 80/90, 89.0\% males; mean height $1.73 \mathrm{~m}$, SD 0.7 ; mean weight $82.9 \mathrm{~kg}$, SD 13; mean body mass index $27.5 \mathrm{~kg} / \mathrm{m}^{2}$, SD 3.4) who successfully completed a 3-month ambulatory CR program were randomly allocated to one of three groups: home-based (30), center-based (30), or control group (30) on a 1:1:1 basis. Home-based patients received a home-based exercise intervention with telemonitoring guidance consisting of weekly emails or phone calls; center-based patients continued the standard in-hospital CR, and control group patients received the usual care including the advice to remain physically active. All the patients underwent cardiopulmonary exercise testing for assessment of their peak oxygen uptake $\left(\mathrm{VO}_{2} \mathrm{P}\right)$ at baseline and after a 12-week intervention period. Secondary outcomes included physical activity behavior, anthropometric characteristics, traditional cardiovascular risk factors, and quality of life.

Results: Following 12 weeks of intervention, the increase in $\mathrm{VO}_{2} \mathrm{P}$ was larger in the center-based $(P=.03)$ and home-based $(P=.04)$ groups than in the control group. In addition, oxygen uptake at the first $(P$-interaction $=.03)$ and second $(P$-interaction=.03) ventilatory thresholds increased significantly more in the home-based group than in the center-based group. No significant changes were observed in the secondary outcomes.

Conclusions: Adding a home-based exercise program with telemonitoring guidance following completion of a phase II ambulatory $\mathrm{CR}$ program results in further improvement of physical fitness and is equally as effective as prolonging a center-based CR in patients with CAD.

Trial Registration: ClinicalTrials.gov NCT02047942; https://clinicaltrials.gov/ct2/show/NCT02047942 (Archived by WebCite at http://www.webcitation.org/70CBkSURj)

(J Med Internet Res 2018;20(6):e225) doi: 10.2196/jmir.9943 


\section{KEYWORDS}

cardiac rehabilitation; telemonitoring; exercise; coronary artery disease

\section{Introduction}

Cardiovascular diseases (CVD) remain the leading contributor to global premature mortality and morbidity. In Europe, more than 4 million people die from CVD every year, with more than 1.4 million dying before the age of 75 years [1]. Today, secondary prevention of CVD, including coronary artery disease (CAD), by means of cardiac rehabilitation (CR) is considered a class IA recommendation by the European Society of Cardiology, American Heart Association, and American College of Cardiology [2]. CR is now recognized as an essential part of contemporary $\mathrm{CAD}$ management that has significantly contributed to the observed reduction in cardiovascular mortality and disability by facilitating the adoption of and adherence to healthy behaviors and promoting an active lifestyle [3]. However, the majority of patients fail to achieve secondary prevention targets in the long term [4]. Many patients receiving center-based CR adopt healthier lifestyles but relapse into old habits when returning to everyday life. After completion of a structured, supervised, exercise-based CR program without any extended support or follow-up, the assumption, of both the participant and CR staff, is that the patient will be able to self-maintain these appropriate health behaviors and optimal CVD risk profile. Unfortunately, studies have shown that patients exiting center-based CR have difficulty retaining the positive benefits derived from their participation [5]. Moreover, previous reports indicate decreased exercise adherence and increased body weight and serum lipid levels as early as 6 months after CR [4,6].

Consequently, there is a need for innovative CR methods to increase long-term adherence to a physically active lifestyle that will result in more sustained effects on health-related physical fitness and cardiovascular health, thus, reducing morbidity and mortality [7]. One attractive strategy is the use of home-based exercise training in combination with telemonitoring guidance. Home-based programs may overcome barriers associated with participation in a center-based exercise program, and they have been shown to provide comparable long-term effects on mortality, recurrent coronary event risk, and cardiovascular risk factors in patients with CVD [8]. This has been attributed partly to the fact that home-based interventions focus more on the development of self-regulatory techniques that create empowerment and perceived control, resulting in longer lasting effects on physical activity improvements [9]. That is, individuals who develop their own physical activity plans are more likely to adhere to these plans than those who have a structured exercise plan imposed on them [9]. The use of information and communication technology to augment home-based programs also enables the provision of additional feedback, education, and counseling [8].

A recent meta-analysis by Buckingham et al [10] found no significant differences in the short-term $(<12$ months) or long-term ( $>12$ months) patient outcomes including exercise capacity, modifiable risk factors (blood pressure, blood lipid concentrations, and smoking), health-related quality of life
(HRQoL), and cardiac events (mortality, coronary revascularization, and hospital readmissions) among patients participating in home-based or center-based phase II CR. However, there is little evidence about the added benefits of a home-based exercise program for patients being discharged from center-based CR compared with advice only.

In this paper, we report on the secondary objective of the TeleRehabilitation in Coronary Heart disease (TRiCH) study. We aimed to investigate the short-term effect of an HR CR program with telemonitoring guidance on physical fitness and other secondary outcomes in CHD patients following completion of a center-based CR program. We also aimed to compare the effectiveness of this program with that of a prolonged center-based CR program by means of a randomized controlled trial (NCT02047942). The longer-term results of the TRiCH study will be published in a second report.

\section{Methods}

\section{Study Design}

We conducted a randomized controlled trial using a three-arm, parallel group design among 90 low-to-moderate risk CAD patients completing a phase II CR program at the University Hospital Leuven (Belgium). The study protocol was approved by the medical ethical committee of the UZ Leuven/KU Leuven. The protocol has been described in detail elsewhere [7].

\section{Patient Population and Randomization}

Patients were recruited between February 2014 and August 2016 at the University Hospital Leuven (Belgium). The eligible patients included men and women (aged between 40 and 75 years) with angiographically-documented CAD or previous myocardial infarction, on optimal medical treatment for the last 6 weeks, who successfully completed a supervised ambulatory $\mathrm{CR}$ program and who had access to a computer with Internet connection. The exclusion criteria included known clinically significant ventricular arrhythmia or exercise-induced arrhythmia at screening, myocardial ischemia, other cardiac diseases (valve disease with significant hemodynamic consequences, hypertrophic cardiomyopathy, etc), significant illness for the last 6 weeks, co-morbidity that might represent a significant influence on 1-year prognosis (eg, cancer), and co-morbidity that limits exercise testing and/or training. The criteria for ischemia on the electrocardiogram during exercise included horizontal or downsloping ST depression $\geq 1 \mathrm{~mm}$ at $80 \mathrm{~ms}$ after the J-point or any ST depression $>1 \mathrm{~mm}$ at $80 \mathrm{~ms}$ after the J-point [11]. The eligible patients were contacted in the last weeks of their in-hospital ambulatory CR program (phase II) and were provided verbal information about the TRiCH study. Agreeing patients subsequently received written information and were asked to provide written informed consent according to the principles of Good Clinical Practice and the Declaration of Helsinki. 


\section{Procedures}

All the agreeing patients who had completed 40 sessions of their ambulatory CR program (phase II) were included and were subsequently randomized in a 1:1:1 ratio to one of three groups: home-based group, center-based group, or a usual care control group by means of a web-based random number generator.

The home-based CR group received training for the first three sessions under the supervision of the investigator. During this period, the patients received an individualized aerobic exercise prescription recommending at least $150 \mathrm{~min}$ of exercise per week (preferably 6-7 days/week) at an individually determined target heart rate corresponding to a moderate intensity (ie, $70 \%-80 \%$ of heart rate reserve [HRR]) in their home environment during the 12-week intervention. Furthermore, this group received instructions on how to use the heart rate monitor (Garmin Forerunner 210, Wichita USA) and how to upload their exercise data to the Garmin platform [12]. This application was used to review the training data by both the patient and the investigator [13]. Patients received feedback via phone or email once a week according to their preferences. These contact moments were used for the following purposes: 1) to check for adverse events and injuries, 2) to provide feedback on performed exercise during the preceding week, 3 ) to discuss the exercise program regarding duration and intensity, and 4) to discuss adherence and barriers to adherence if necessary.

Patients randomized to center-based CR continued their exercise program at the outpatient clinic of UZ Leuven under the direct supervision of physiotherapists. The patients were asked to perform three exercise sessions per week totaling approximately $150 \mathrm{~min}$ of endurance exercise. Each training session consisted of predominantly endurance training $(2 \times 7 \mathrm{~min}$ of cycling, $2 \times 7$ min of treadmill walking/running, 7 min of arm ergometry or rowing, and $2 \times 7$ min of dynamic calisthenics) and was followed by relaxation. The endurance exercise workload was individually controlled by heart rate monitoring, which was performed by palpation by the physiotherapist during the last minute of each round of exercise. Exercise load was adjusted to maintain target heart rate $(70 \%-80 \%$ of the HRR). Patients randomized to the control group received usual care including the standard advice to remain physically active.

\section{Primary Outcome Measure}

Primary outcome was change in the exercise capacity following the intervention. Exercise capacity (defined as the maximum amount of physical exertion that a patient could sustain) [14] was determined at baseline and at the end of the intervention using a maximally graded test on a bicycle with breath-by-breath respiratory gas analysis (Ergometrics 800S, Ergometrics, Bitz, Baden-Württemberg, Germany). Peak exercise capacity was defined as the 30-s average oxygen uptake $\left(\mathrm{VO}_{2}\right)$ at the highest workload [7]. Ventilatory thresholds (VTs), peak respiratory exchange ratio, and peak heart rate were also established [7].

\section{Secondary Outcome Measures}

Secondary outcomes included daily physical activity, measured using a Sensewear Mini Armband (BodyMedia, Inc., Pittsburgh, PA, USA). Steps, sedentary time (duration of sedentary activity at an intensity of $\leq 1.5$ metabolic equivalents of task [METs], $\mathrm{min}$ ), active energy expenditure (physical activity at an intensity of $\geq 3$ METs, kcal), and duration of moderate and vigorous physical activity ( $\geq 3$ METs, min) were used in the analyses [15]. Oxygen uptake on-kinetics were established at least $48 \mathrm{~h}$ after the maximal exercise test and was calculated algebraically and expressed as mean response time [7]. Sitting-rising test (SRT), handgrip strength (JAMAR grip strength dynamometer), and quadriceps maximal isometric knee extension strength and endurance (Biodex Medical Systems Inc., 840-000 System 4, New York, USA) were obtained along with traditional cardiovascular risk factors such as anthropometric measures (body mass index, waist and hip circumference) and biochemical parameters of a fasting blood sample (glucose, total cholesterol, low-density lipoprotein [LDL] cholesterol, high-density lipoprotein [HDL] cholesterol, and triglycerides). Additionally, homeostasis assessment model (HOMA) [16] index was calculated using the following formula: fasting plasma glucose $(\mathrm{mmol} / \mathrm{L})$ times fasting serum insulin $(\mathrm{mU} / \mathrm{L})$ divided by 22.5 . Low HOMA-IR values indicated high insulin sensitivity, whereas high HOMA-IR values indicated low insulin sensitivity (insulin resistance). For this study, patients with HOMA-IR $\geq$ 3.8 were considered to be insulin resistant [17]. Finally, HRQoL was obtained by means of the standard version of the Short Form 36 [7].

\section{Analysis}

All data were expressed as mean (SD) or median, range, or percentages (for categorical variables). Statistical analyses were performed using SPSS (version 20; SPSS for windows; SPSS Inc., Chicago, IL). Shapiro-Wilk test was used to assess normality. At baseline, the groups were compared using one-way analysis of variance or chi-square tests. For follow-up data, a linear mixed modeling method was used to evaluate time, group, and time $\times$ group interaction effects. The analysis was complemented with a matrix syntax code including a least significant difference post-hoc test when a significant time $\times$ group interaction identified a group that significantly differed over time. An intention-to-treat analysis was performed on the primary outcome (peak oxygen uptake, $\mathrm{VO}_{2} \mathrm{P}$ ), and on-treatment analysis was used for secondary outcomes. Spearman correlation coefficients $(p)$ were calculated between $\mathrm{VO}_{2} \mathrm{P}$ and active energy expenditure and physical activity duration at 12 weeks. A probability level of $P \leq 0.05$ was considered significant.

\section{Results}

A total of $90 \mathrm{CAD}$ patients agreed to participate and were randomized to home-based group $(n=30)$, center-based group $(n=30)$, and control group group $(n=30)$. Figure 1 shows the flow of patients throughout the study. Six patients, (4 men: control group, $n=4$; home-based, $n=2$ ) dropped out during the 3 -month intervention period. Reasons for dropout included loss of interest (control group, $n=2$; home-based, $n=2$ ) and a new cardiac intervention (ie, percutaneous coronary intervention) (control group, $\mathrm{n}=2$ ). No serious adverse events related to exercise occurred in any of the groups. 
Figure 1. Flow of patients through the study.

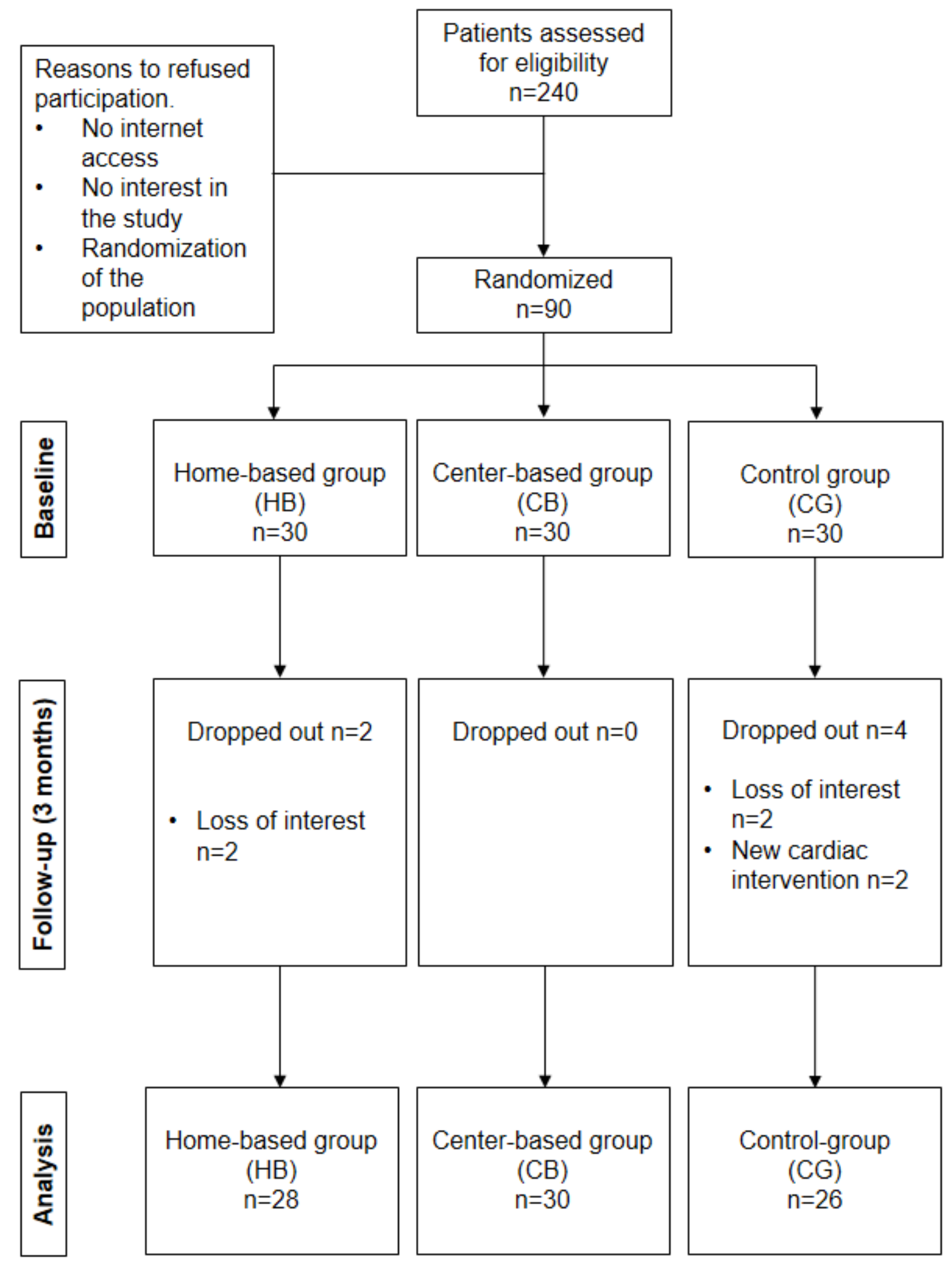

The basic characteristics of the study population are described in Table 1. The mean age of the participants was 61.4 (SD 7.3) years (range: $42-73$ years). A total of 10 (11.1\%) women participated in the study, and patients were on average slightly overweight, 27.5 (SD $3.4 \mathrm{~kg} / \mathrm{m}^{2}$ ). Overall, exercise capacity was normal, 101.1\% (SD 21.1) compared with reference values [18]. Baseline characteristics were comparable between the groups regarding physical characteristics, reason for referral, and pharmacological therapy. 


\section{Primary Outcome Measure}

Changes in cardiorespiratory parameters are described in Table 2. As can be appreciated from peak respiratory exchange ratios (RER), participants in all three groups exerted a similar maximal effort at baseline and follow-up. The pattern of change in $\mathrm{VO}_{2}$ $\mathrm{P}$ differed significantly over time among the three groups (group $\times$ time interaction, $P=.04$ ), with a larger improvement following home-based $(P=.03)$ and center-based $(P=.04)$ interventions than control group interventions. Group $\times$ time interactions were also established for $\mathrm{O}_{2}$ uptake at the first ventilatory threshold $\left(\mathrm{VT}_{1} ; P\right.$-interaction=.03) and the second ventilatory threshold $\left(\mathrm{VT}_{2} ; P\right.$-interaction=.03), with larger improvements in the home-based group than in the control group.

\section{Secondary Outcome Measures}

Changes in daily physical activity are shown in Table 3. Physical activity behavior remained constant after the intervention ( $P$-time=.73). Of all the patients, 97.0\% (84/90) met the international guidelines of $150 \mathrm{~min}$ or more of moderate physical activity per week [19]. In addition, a significant increase in sedentary time in the center-based group $(P$-interaction=.02) was found. No significant correlation of change in $\mathrm{VO}_{2} \mathrm{P}$ with change in active energy expenditure (Spearman $\mathrm{p}=-.14 ; P=.40$ ) or change in physical activity duration $(\rho=.09 ; P=.44)$ was found. However, a significant correlation of $\mathrm{VO}_{2} \mathrm{P}$ with physical activity duration $(\rho=.53 ; P<.001)$ at 12 weeks as well as with active energy expenditure $(\rho=.37 ; P<.001)$ was found.

Table 1. Baseline characteristics of patients.

\begin{tabular}{|c|c|c|c|}
\hline Characteristics & Home-based $(\mathrm{n}=30)$ & Center-based $(\mathrm{n}=30)$ & Control $(n=30)$ \\
\hline \multicolumn{4}{|l|}{ General characteristics } \\
\hline Age (years), mean (SD) & $58.6(13)$ & $61.9(7.3)$ & $61.7(7.7)$ \\
\hline Female, n $(\%)$ & $4(13)$ & $3(10)$ & $3(10)$ \\
\hline$\%$ of Predicted peakVO ${ }_{2}{ }^{\mathrm{a}}$, mean $(\mathrm{SD})$ & $99.9(23.1)$ & $99.3(20.1)$ & $105.2(20.2)$ \\
\hline \multicolumn{4}{|l|}{ Reason for referral, n (\%) } \\
\hline $\mathrm{CABG}^{\mathrm{b}}$ & $18(60)$ & $18(60)$ & $20(67)$ \\
\hline $\mathrm{PCI}^{\mathrm{c}}$ & $12(40)$ & $12(40)$ & $10(33)$ \\
\hline \multicolumn{4}{|l|}{ Cardiovascular risk factors, $n(\%)$} \\
\hline Familial predisposition & $12(40)$ & $8(27)$ & $13(43)$ \\
\hline Hypertension & $14(47)$ & $11(37)$ & $17(57)$ \\
\hline Diabetes & $12(40)$ & $8(27)$ & $4(13)$ \\
\hline Dyslipidemia & $15(50)$ & $17(57)$ & $19(63)$ \\
\hline \multicolumn{4}{|l|}{ Smoking } \\
\hline Never-smoker & $11(37)$ & $14(47)$ & $15(50)$ \\
\hline Ex-smoker & $16(53)$ & $15(50)$ & $15(50)$ \\
\hline Current-smoker & $3(10)$ & $1(3)$ & $0(0)$ \\
\hline \multicolumn{4}{|l|}{ Medication, n (\%) } \\
\hline Anti-hypertensive $^{\mathrm{d}}$ & $23(77)$ & $27(90)$ & $24(80)$ \\
\hline Beta Blockers & $21(70)$ & $23(77)$ & $25(83)$ \\
\hline Statins & $28(93)$ & $29(97)$ & $28(93)$ \\
\hline Aspirin & $29(97)$ & $27(90)$ & $29(97)$ \\
\hline Anti-thrombotic & $19(63)$ & $18(60)$ & $23(77)$ \\
\hline Anti-arrhythmic & $1(3)$ & $1(3)$ & $0(0)$ \\
\hline Hypoglycemic & $4(13)$ & $8(27)$ & $4(13)$ \\
\hline Vasodilators & $0(0)$ & $1(3)$ & $2(7)$ \\
\hline
\end{tabular}

${ }^{\mathrm{a}} \mathrm{VO}_{2}$ : oxygen uptake.

${ }^{\mathrm{b}} \mathrm{CABG}$ : coronary artery bypass graft.

${ }^{\mathrm{C}} \mathrm{PCI}$ : percutaneous coronary intervention.

${ }^{\mathrm{d}}$ Anti-hypertensive medication: warfarine and clopidogrel. 
Table 2. Changes in cardiorespiratory parameters at baseline and 3-month follow-up.

\begin{tabular}{|c|c|c|c|c|c|c|c|c|c|}
\hline \multirow[t]{2}{*}{ Parameter } & \multicolumn{2}{|c|}{$\begin{array}{l}\text { Home-based }(n=28), \text { mean } \\
(\mathrm{SD})\end{array}$} & \multicolumn{2}{|c|}{$\begin{array}{l}\text { Center-based }(n=30), \text { mean } \\
(\mathrm{SD})\end{array}$} & \multicolumn{2}{|c|}{ Control $(n=26)$, mean (SD) } & \multicolumn{3}{|c|}{$P$ value } \\
\hline & Baseline & 3-Month & Baseline & 3-Month ${ }^{\mathrm{a}}$ & Baseline & 3-Month & Time & Group & Interaction \\
\hline $\begin{array}{l}\mathrm{VO}_{2} \text { peak } \\
\left(\mathrm{mL} \cdot \mathrm{kg}^{-1} \cdot \mathrm{min}^{-1}\right)\end{array}$ & $26.7(6.55)$ & $27.8(6.83)$ & $25.4(7.32)$ & $26.7(7.90)$ & $26.6(4.97)$ & $26.4(5.42)$ & .08 & .69 & $.04^{\mathrm{b}}$ \\
\hline $\mathrm{VT}^{\mathrm{a}}\left(\mathrm{mL} \cdot \mathrm{kg}^{-1} \cdot \mathrm{min}^{-1}\right)$ & $19.5(1.07)$ & $21.5(1.07)$ & $19.5(1.04)$ & $20.4(1.04)$ & $19.9(1.08)$ & $19.3(1.11)$ & .81 & .06 & $.03^{, b}$ \\
\hline $\mathrm{VT}^{\mathrm{c}}\left(\mathrm{mL} \cdot \mathrm{kg}^{-1} \cdot \mathrm{min}^{-1}\right)$ & $24.9(5.25)$ & $26.3(6.98)$ & $22.7(6.95)$ & $24.2(7.13)$ & $24.7(5.08)$ & $22.9(4.19)$ & .41 & .49 & $.03^{, \mathrm{b}}$ \\
\hline Duration (s) & $570(136)$ & $587(157)$ & $549(133)$ & $552(157)$ & $600(126)$ & $579(116)$ & .89 & .52 & .23 \\
\hline Peak heart rate (bpm) & $140(18.8)$ & $139(17.8)$ & $141(21.5)$ & $140(21.1)$ & $140(18.9)$ & $140(16.6)$ & .75 & .97 & .95 \\
\hline Peak load (watts) & $198(49)$ & $200(54)$ & $191(50)$ & $191(54)$ & $206(41)$ & $197(38)$ & .39 & .67 & .15 \\
\hline Borg scale & $15.8(1.16)$ & $15.8(1.33)$ & $16.2(1.04)$ & $16(1.17)$ & $15.9(1.05)$ & $16.2(1.02)$ & .87 & .45 & .38 \\
\hline
\end{tabular}

${ }^{\mathrm{a}}$ VT1: first ventilatory threshold.

${ }^{\mathrm{b}} P$ - interaction $<.05$.

${ }^{\mathrm{c}}$ VT2: second ventilatory threshold.

${ }^{\mathrm{d}} \mathrm{RER}$ : respiratory exchange ratios.

Table 3. Changes in daily physical activity at baseline and 3-month follow-up.

\begin{tabular}{|c|c|c|c|c|c|c|c|c|c|}
\hline \multirow[t]{2}{*}{ Physical activity } & \multicolumn{2}{|c|}{$\begin{array}{l}\text { Home-based }(n=24), \text { mean } \\
\text { (range) }\end{array}$} & \multicolumn{2}{|c|}{$\begin{array}{l}\text { Center-based }(n=28), \text { mean } \\
\text { (range) }\end{array}$} & \multicolumn{2}{|c|}{$\begin{array}{l}\text { Control }(n=26), \text { mean } \\
\text { (range) }\end{array}$} & \multicolumn{2}{|c|}{$P$ value } & \multirow[b]{2}{*}{ Interaction } \\
\hline & Baseline & 3-Month & Baseline & 3-Month & Baseline & 3-Month & Time & Group & \\
\hline Steps per day & $\begin{array}{l}7896(2018- \\
12554)\end{array}$ & $\begin{array}{l}6469(473- \\
12828)\end{array}$ & $\begin{array}{l}7608(2474- \\
13281)\end{array}$ & $\begin{array}{l}7065(489- \\
14785)\end{array}$ & $\begin{array}{l}6419(2227- \\
13181)\end{array}$ & $\begin{array}{l}6408(296- \\
12041)\end{array}$ & .18 & .56 & .18 \\
\hline $\begin{array}{l}\text { Sedentary time }(\leq 1.5 \\
\text { METs; min/day })\end{array}$ & $\begin{array}{l}1039(688- \\
1260)\end{array}$ & $\begin{array}{l}1032(790- \\
1455)\end{array}$ & $\begin{array}{l}1005(122- \\
1290)\end{array}$ & $\begin{array}{l}1094(857- \\
1254)^{\mathrm{a}}\end{array}$ & $\begin{array}{l}1100(825- \\
1355)\end{array}$ & $\begin{array}{l}1062(484- \\
1402)\end{array}$ & .56 & .43 & $.02^{\mathrm{b}}$ \\
\hline $\begin{array}{l}\text { Active energy expendi- } \\
\text { ture (>3METs; kcal) }\end{array}$ & $\begin{array}{l}1336(351- \\
3217)\end{array}$ & $\begin{array}{l}1307(661- \\
2246)\end{array}$ & $\begin{array}{l}1137(484- \\
2539)\end{array}$ & $\begin{array}{l}1244(549- \\
2745)\end{array}$ & $\begin{array}{l}1223(401- \\
2253)\end{array}$ & $\begin{array}{l}1196(181- \\
2510)\end{array}$ & .56 & .40 & .45 \\
\hline $\begin{array}{l}\text { Physical activity dura- } \\
\text { tion (>3METs; } \\
\text { min/day) }\end{array}$ & $145(34-299)$ & $141(51-259)$ & $146(28-417)$ & $134(29-366)$ & $114(30-311)$ & $114(6-382)$ & .73 & .27 & .47 \\
\hline $\begin{array}{l}\text { Vigorous physical activ- } \\
\text { ity duration (>6 METs; } \\
\mathrm{min} / \text { day) }\end{array}$ & $8(0-33)$ & $7(0-24)$ & $6(0-26)$ & $6(0-24)$ & $5(0-20)$ & $2(0-27)$ & .50 & .21 & .59 \\
\hline
\end{tabular}

${ }^{\mathrm{a}}$ METs: metabolic equivalents of task.

${ }^{\mathrm{b}} P$ - interaction $<.05$.

As shown in table Table 4, isometric handgrip strength (HG), isometric quadriceps strength, and endurance, as well as exercise-onset oxygen uptake on-kinetics remained stable during the follow-up period. Additionally, cardiovascular risk factors (Figure 2) and anthropometrics (Table 5) were similar between the groups at baseline and remained stable during the follow-up period, except for an increase in HOMA index $(P$-time $=.05)$, which was not different between the groups. Finally, there were no significant changes in the overall score for HRQoL $(P$-interaction $=.57)$ as well as the physical $(P$-interaction $=.50)$ and mental $(P$-interaction $=.85)$ composite scores. Table 6 shows HRQoL from baseline and follow-up evaluations.

\section{Training Data}

Patients in the home-based group completed an average of 2.5 sessions per week (range: 12-60 sessions for 12 weeks), whereas those in the center-based group completed an average of 2.0 sessions per week (range: 4-36 sessions for 12 weeks). Patients in the home-based group exercised for an average $164 \mathrm{~min}$ per week at an average intensity of $46.8 \%$ of HRR (76.7 min within the prescribed zone). Patients in the center-based group 
exercised for an average $90 \mathrm{~min}$ per week at an average intensity of $61.2 \%$ of HRR.

Table 4. Changes in muscle strength and exercise-onset oxygen uptake $\left(\mathrm{VO}_{2}\right)$ kinetics.

\begin{tabular}{|c|c|c|c|c|c|c|c|c|c|}
\hline \multirow[t]{2}{*}{ Parameter } & \multicolumn{2}{|c|}{$\begin{array}{l}\text { Home-based }(n=23) \text {, mean } \\
(\mathrm{SD})\end{array}$} & \multicolumn{2}{|c|}{$\begin{array}{l}\text { Center-based }(n=29) \text {, mean } \\
(\mathrm{SD})\end{array}$} & \multicolumn{2}{|c|}{ Control (n=19), mean (SD) } & \multicolumn{3}{|c|}{$P$ value } \\
\hline & Baseline & 3-Month & Baseline & 3-Month & Baseline & 3-Month & Time & Group & Interaction \\
\hline \multicolumn{10}{|l|}{ Muscle strength } \\
\hline Handgrip strength (kg) & $43.1(10.5)$ & $44.7(12.3)$ & $40.2(8.6)$ & $41.2(8.3)$ & $41.6(8.3)$ & $43.8(9.3)$ & .99 & .23 & .23 \\
\hline $\begin{array}{l}\text { Isometric quadriceps } \\
\text { extension }\left(60^{\circ} \mathrm{Nm}\right)\end{array}$ & $151.8(28)$ & $164.1(37)$ & $150.5(44.9)$ & $155(43.4)$ & $148.7(30)$ & $148.8(28.3)$ & .23 & .47 & .86 \\
\hline Extension total work $(\mathrm{J})$ & $1614(680)$ & $1976(718)$ & $1758(756)$ & 1893 (717) & 1694 (796) & $1906(689)$ & .09 & .94 & .52 \\
\hline \multicolumn{10}{|l|}{ Exercise-Onset $\mathrm{VO}_{2}{ }^{\mathrm{i}}$ kinetics } \\
\hline Average $\mathrm{MRT}^{\mathrm{a}}(\mathrm{s})$ & $45.5(16.2)$ & $39.8(9.3)$ & $38.7(8.1)$ & $40.8(9.1)$ & $39.8(16.9)$ & $43.6(22)$ & .98 & .64 & .19 \\
\hline
\end{tabular}

${ }^{\mathrm{a}} \mathrm{MRT}$ : mean response time. 
Figure 2. Cardiovascular risk factors.No significant changes were found in cardiovascular risk factors for total cholesterol $(P$-interaction=.82), HDL-cholesterol $(P$-interaction=.69), LDL-cholesterol $(P$-interaction=.79), triglycerides $(P$-interaction=.27), fasting glucose $(P$-interaction=.71), HOMA index $(P$-interaction=.93). Dark gray column: home-based group, White column: center-based group, Light grey column: control group. HDL: high-density lipoprotein; HOMA: homeostasis assessment; LDL: how-density lipoprotein.
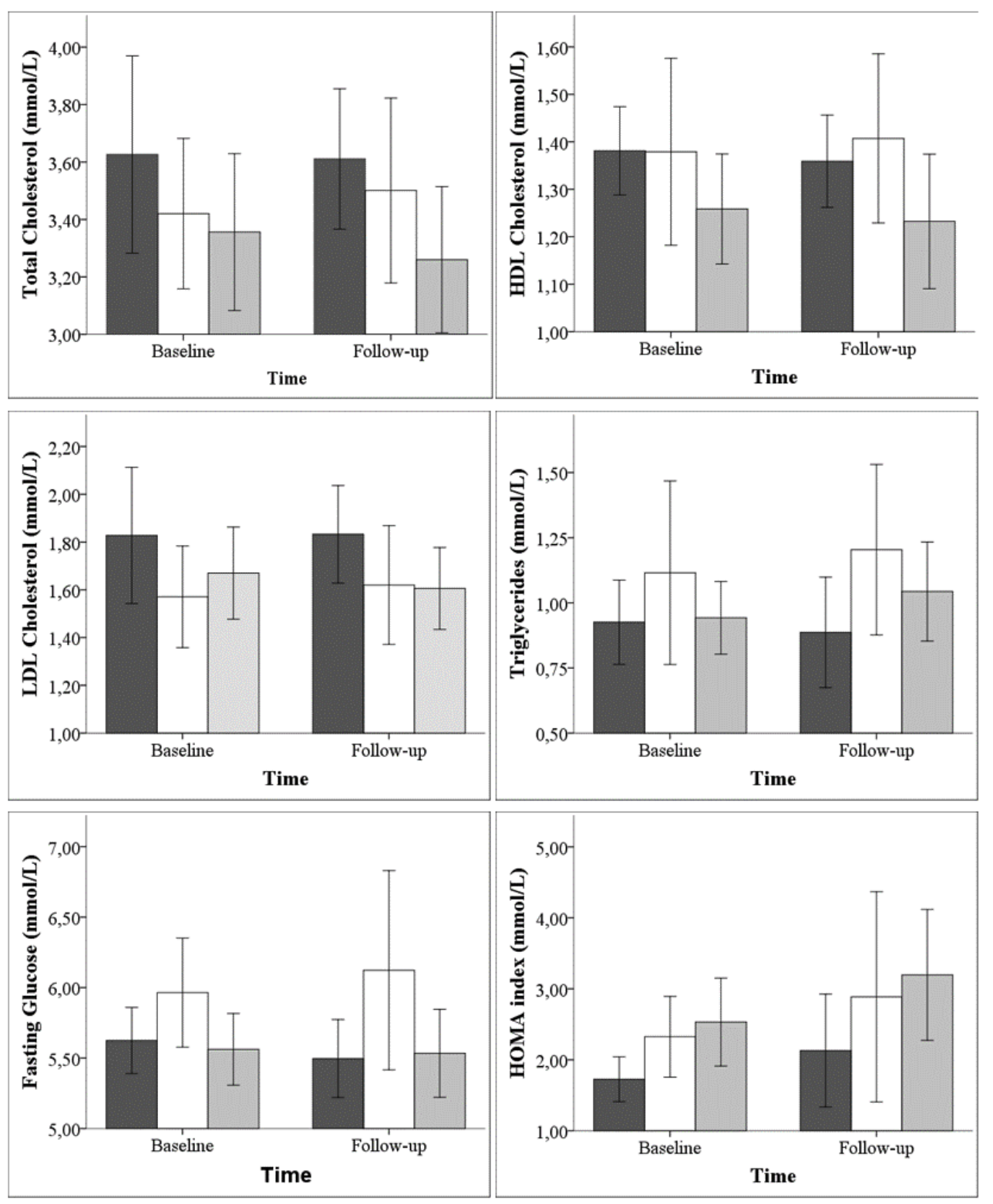
Table 5. Outcomes at baseline and 3-month follow-up regarding anthropometric parameters.

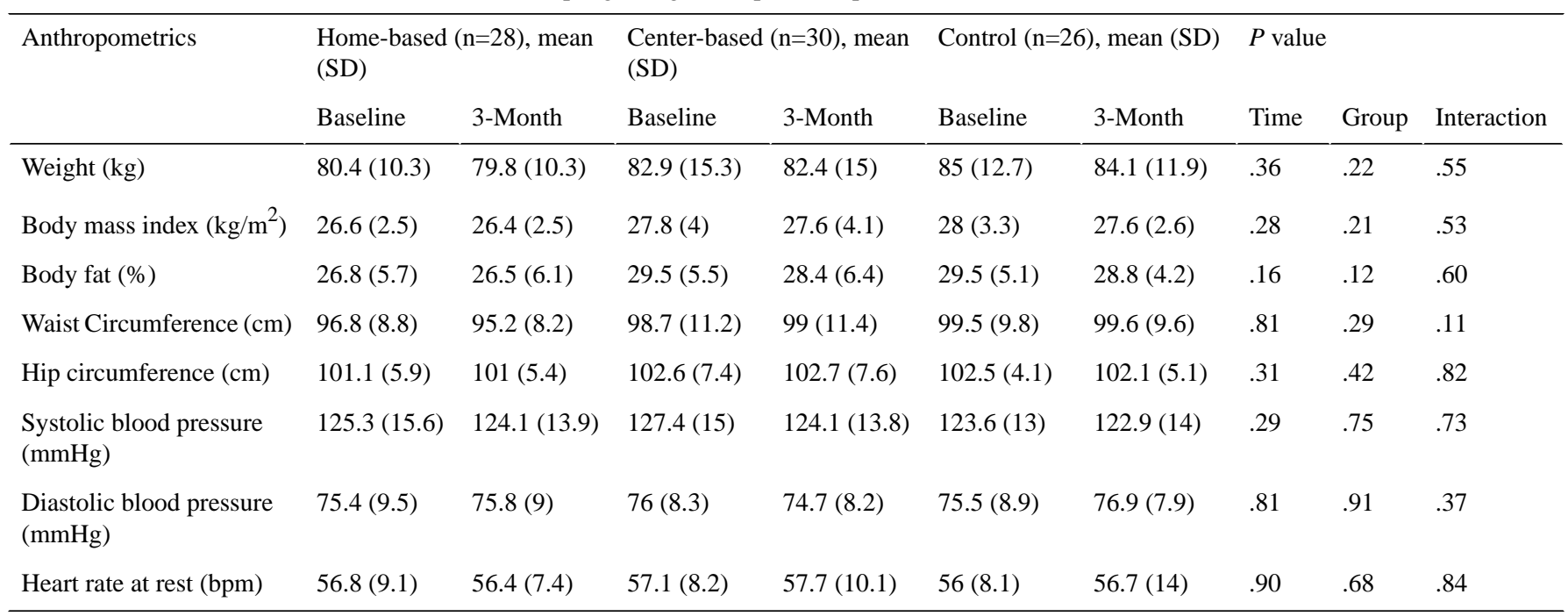

Table 6. Changes in health-related quality of life (HRQoL).

\begin{tabular}{|c|c|c|c|c|c|c|c|c|c|}
\hline \multirow[t]{2}{*}{ HRQoL measures } & \multicolumn{2}{|c|}{$\begin{array}{l}\text { Home-based }(n=28), \text { mean } \\
(\mathrm{SD})\end{array}$} & \multicolumn{2}{|c|}{$\begin{array}{l}\text { Center-based }(n=30), \text { mean } \\
(\mathrm{SD})\end{array}$} & \multicolumn{2}{|c|}{ Control $(n=26)$, mean (SD) } & \multicolumn{3}{|c|}{$P$ value } \\
\hline & Baseline & 3-Month & Baseline & 3-Month & Baseline & 3-Month & Time & Group & Interaction \\
\hline Physical Function & $90(10.7)$ & $91.9(7.6)$ & $85.3(15.6)$ & $87.4(13.6)$ & $81.4(15.7)$ & $84.3(16.1)$ & .19 & .04 & .49 \\
\hline Role-physical function & $83.6(27.3)$ & $87.5(28.4)$ & $74.2(36.6)$ & $83.9(31.3)$ & $58(41.4)$ & $61.4(38.9)$ & .15 & .00 & .43 \\
\hline Bodily pain & $84.2(13.7)$ & $80.9(17.7)$ & $82.5(19.2)$ & $83.8(23.3)$ & $72.7(23.3)$ & $77.6(23.2)$ & .83 & .11 & .70 \\
\hline General health & $74.2(13.1)$ & $75.2(18.7)$ & $75.7(13.6)$ & $72.4(22.9)$ & $64.2(16.6)$ & $71.5(19.1)$ & .41 & .17 & .17 \\
\hline Vitality & $72.8(13.9)$ & $71(13.4)$ & $69.3(15.6)$ & $74.6(15.4)$ & $65.3(14.6)$ & $63.9(20)$ & .70 & .06 & .10 \\
\hline Social function & $87.6(16.7)$ & $90.6(16.5)$ & $86.6(17.3)$ & $89.1(15.7)$ & $83.7(18.2)$ & $89.5(17.5)$ & .20 & .81 & .90 \\
\hline Role-emotional function & $84.6(27)$ & $86.8(22.8)$ & $84.5(33.3)$ & $86.8(29.1)$ & $86.2(30.2)$ & $84.7(31)$ & .73 & .99 & .79 \\
\hline Mental health & $78.6(15.6)$ & $77.5(17.6)$ & $79.3(13.3)$ & $81.4(15)$ & $78.2(15.6)$ & $76.6(21.1)$ & .91 & .72 & .59 \\
\hline Physical Composite Score & $80.9(12.3)$ & $81.3(13.1)$ & $77.2(15.2)$ & $80.8(16.3)$ & $67.9(17.1)$ & $71.8(18.3)$ & .008 & .07 & .50 \\
\hline Mental Composite Score & $79.8(13.7)$ & $80.2(13.5)$ & $77.5(18)$ & $81.3(15.5)$ & $75.1(13.8)$ & $77.2(16.2)$ & .06 & .38 & .85 \\
\hline $\mathrm{SF}-36^{\mathrm{a}}$ & $82.2(13.3)$ & $82.6(13)$ & $79.8(16.1)$ & $82.6(15.8)$ & $73.3(15.1)$ & $76.4(16.4)$ & .07 & .06 & .57 \\
\hline
\end{tabular}

${ }^{\mathrm{a}} \mathrm{SF}-36$ : Short Form 36. Scores of the domains of the SF-36: 0=worst and 100=best score.

\section{Discussion}

The significant finding of our randomized controlled study is that a 3-month home-based rehabilitative intervention with telemonitoring guidance results in further improvement of exercise capacity $\left(\mathrm{VO}_{2} \mathrm{P}\right)$ in $\mathrm{CAD}$ patients who had recently completed a phase II ambulatory program, and a home-based program is as effective as a prolonged center-based CR. The observed improvements of $1.30 \mathrm{~mL} \cdot \mathrm{kg}^{-1} \cdot \mathrm{min}^{-1}$ and 1.10 $\mathrm{mL} \cdot \mathrm{kg}^{-1} \cdot \mathrm{min}^{-1}$ in $\mathrm{VO}_{2} \mathrm{P}$ of center-based and home-based groups, respectively, are likely to be clinically relevant. It has been shown in earlier studies that a $1 \mathrm{~mL} \cdot \mathrm{kg}^{-1} \cdot \mathrm{min}^{-1}$ increase in exercise capacity is associated with a $10 \%$ reduction in cardiovascular mortality [20]. Thus, our results support the added value of a structured continued rehabilitation program.
There are only few studies in the literature that have investigated the effectiveness of a home-based, telemonitored, phase III CR program starting immediately after completion of a phase II center-based CR program. A small proof-of-concept study by Brubaker et al [5] randomly assigned 31 patients to home-based, center-based, or standard care. In line with our results, they found that the home-based program was as effective as the center-based program at improving and maintaining oxygen consumption among patients 9 months after exiting a CR program. In the Telerehab III trial [21], 140 patients were randomized to a telerehabilitation program in addition to conventional CR or conventional CR alone. This study also reported that a 6-month patient-specific comprehensive telerehabilitation program initiated 6 weeks after the start of ambulatory rehabilitation leads to a bigger improvement in $\mathrm{VO}_{2}$ $\mathrm{P}$ and confirmed our results of lack of an additional weight loss, blood pressure reduction, lipid profile improvement, and glycemic control. 
In the last decade, several meta-analyses have been published demonstrating the effectiveness of home-based programs for CAD patients implemented as a phase II CR program [22-24]. Although the increase in $\mathrm{VO}_{2} \mathrm{P}$ of $4 \%-5 \%$ in our phase III center-based and home-based groups is less than what has been seen in previous phase II programs, this is still of clinical relevance, as the purpose of phase III (maintenance phase) CR is to preserve, or if possible, enhance the health benefits gained in phase II. Our results further show that although patients in the home-based group exercised only 75 min per week at the prescribed intensity and the average intensity was below the recommended thresholds, patients were still able to further increase their exercise capacity compared with those in the control group who receive only advice on how to maintain a physically active lifestyle. This is in line with meta-analytic results of Swain and Franklin [25], demonstrating that in healthy individuals with a mean baseline $\mathrm{VO}_{2 \max }<40 \mathrm{~mL} \cdot \mathrm{kg}^{-1} \cdot \mathrm{min}^{-1}$, there is no clear minimal intensity threshold to increase their aerobic capacity and that patients already show improvements when exercising at an intensity of $40 \%$ of HRR. Yet, there is abundant evidence that larger effects on health and fitness are established when individuals exercise at higher intensities and larger duration [26].

Regarding physical activity, Ayabe et al [27], reported that 6500-8500 steps/day should be considered as the minimal and optimal goal of physical activity for secondary prevention of CVD. With the number of steps ranging between 7612 (home-based) and 7700 (center-based), the patients in the home-based and center-based groups were within this target zone, whereas those in the control group (5566) did not seem to reach this goal. However, we were not able to promote an additional increase in the number of daily steps. These results are in line with previous studies that have demonstrated how exercise interventions focused on physical fitness improvement in cardiac patients do not influence the improvement of physical activity $[21,28,29]$.

We observed, however, a small but significant increase in sedentary time in the center-based group. Evidence suggests that those participating in exercise-focused interventions are not likely to reduce their sedentary time by a meaningful amount [30]. King et al [31] explained this behavior as a compensatory effect for exercise. That is, the simple fact of enrolling in a supervised exercise program might reduce physical activity levels throughout the rest of the day. This compensatory effect acts in different ways by promoting adjustments in energy expenditure in order to save energy or recover from the exercise training, consequently, increasing the sedentary time [32]. Growing evidence suggest that prolonged sedentary behavior can affect cardiovascular and all-cause mortality risk independent of physical activity [33]. Probably, recommendations on sedentary behavior can be included in CR programs, given the current state of the evidence [30].

Small improvements in weight reduction and body composition as well as in blood pressure were observed post-intervention, although this did not reach significance. This is consistent with the findings in the Telerehab III trial [21]. According to Frederix et al, digital health interventions seem to be able to improve cardiovascular risk factors in primary prevention, but not in secondary prevention, programs [21]. Furthermore, we hypothesize that when the pharmacological management of the groups is close to optimal, like in our patients, the incremental benefit of secondary prevention programs over usual care is very small [34].

One of the main objectives of CR is to optimize patients' physical functionality as a means to improve quality of life. In our study, no effects of our interventions on different HRQoL domains could be found. Contrary to our results, Smith et al [35] found clinically significant improvements in HRQoL in their home-based group compared with their hospital-based group after a 6-month intervention. The authors considered that 6 months of CR, regardless of location, was associated with improvements in physical HRQoL. Thus, it is possible that with a longer intervention for both the groups, some differences could have been obtained in our study.

One area that is not commonly considered with $\mathrm{CR}$ is the functional status or abilities of the patient. The typical patient in $\mathrm{CR}$ is over the age of 60 and presents with multiple cardiovascular risk factors, such as inactivity and obesity, and is recovering from a recent cardiac event. All these factors can lead to deficits in balance, mobility, and function. Sumide et al, found that musculoskeletal fitness and flexibility, measured by SRT, was a significant predictor of mortality in 51- to 80-year-old participants [36]. In this study, no significant difference was seen in SRT between the groups $(P=.36)$. Our results are in line with those of Oerkild et al [37]. Regarding components of muscular fitness, Mroszcwyk et al [38] and Thomaes et al [39] found increased HG strength in patients following 3 months of a (predominantly aerobic exercise training) CR program. In our study, however, no changes were observed after 12 weeks of intervention. It is possible that the largest gains in HG strength appear during phase II of CR, while our intervention targeted phase III patients. In addition, we found no significant difference in knee extension strength or resistance after 3 months of home-based or center-based training, which may be explained by the focus on aerobic training during the intervention. These results are also consistent with those of previous studies [40,41]. Conraads et al collected muscle strength data in $75 \mathrm{CAD}$ patients before and after 12 weeks of an aerobic interval training or continuous training CR program, finding that muscle strength did not improve. The authors considered as a possible cause the use of statins that has been associated with negative side effects on the muscles. In our study, 94\% (79/84) of the patients are treated with statins, although insufficient evidence exists to prove that statins really affect muscle strength [42]. Currently, there is very limited evidence regarding the effects of telerehabilitation on muscle strength, and more research is needed [43].

Finally, while short-term changes are of interest, it is important to establish whether the benefits are maintained over time; thus, further research should focus on the long-term effects of home-based CR with telemonitoring guidance.

\section{Limitations}

Our study should be interpreted within the context of its limitations. First, next to physical activity training, CR includes 
other important core components such as nutritional counseling, risk factor management, and psychosocial management. Although physical activity training comprises $30 \%-50 \%$ (up to $>70 \%$ ) of all CR activities, it should be acknowledged that this study evaluates the effect of physical activity telemonitoring rather than telerehabilitation [3]. Second, heart rate monitors were used only in the home-based group as we opted to not change the traditional center-based program where heart rate is measured by palpation by physiotherapists. We were not able to precisely define the exact number of minutes patients spend within the prescribed training zone.

Another limitation of this study is the lack of blinding of test personnel. However, as the main outcome measure was $\mathrm{VO}_{2} \mathrm{P}$, the effort of the participants can be objectively quantified by means of RER and subjectively by means of the Borg scale [44]. The study, as in most randomized controlled trials, has missing outcome data. Regarding muscle strength, 19 values were completely missing at random due to technical problems, and regarding physical activity, the data was incomplete and, thus, excluded for 12 patients.

\section{Conclusion}

The results of our study show that home-based CR with telemonitoring guidance can be an effective alternative to center-based $\mathrm{CR}$ for further improving exercise capacity following phase II CR in CHD patients.

\section{Acknowledgments}

AA is supported by a doctoral research grant funded by the European Commission through MOVE-AGE, an Erasmus Mundus Joint Doctorate programme (2011-2015). RB received a research grant from the Belgian Fund for Cardiac Surgery.

The authors thank the patients who participated in the TRiCH study as well as the staff of the cardiac rehabilitation center in UZ Leuven for their enthusiastic support of this project.

\section{Authors' Contributions}

VC contributed to the conception and design of the work. AA and JC contributed to the acquisition, analysis, or interpretation of data for the work. VC and AA drafted the manuscript. JC, RB, KG, MA, and LV critically revised the manuscript. All the authors gave final approval and agree to be accountable for all aspects of work ensuring integrity and accuracy.

\section{Conflicts of Interest}

None declared.

\section{Multimedia Appendix 1}

CONSORT - EHEALTH checklist (V 1.6.1).

[PDF File (Adobe PDF File), 804KB-Multimedia Appendix 1]

\section{References}

1. Perk J, De BG, Gohlke H, Graham I, Reiner Z, Verschuren M, European Association for Cardiovascular Prevention \& Rehabilitation (EACPR), ESC Committee for Practice Guidelines (CPG). European Guidelines on cardiovascular disease prevention in clinical practice (version 2012). The Fifth Joint Task Force of the European Society of Cardiology and Other Societies on Cardiovascular Disease Prevention in Clinical Practice (constituted by representatives of nine societies and by invited experts). Eur Heart J 2012 Jul;33(13):1635-1701 [FREE Full text] [doi: 10.1093/eurheartj/ehs092] [Medline: 22555213]

2. Piepoli MF, Corrà U, Adamopoulos S, Benzer W, Bjarnason-Wehrens B, Cupples M, et al. Secondary prevention in the clinical management of patients with cardiovascular diseases. Core components, standards and outcome measures for referral and delivery: a policy statement from the cardiac rehabilitation section of the European Association for Cardiovascular Prevention \& Rehabilitation. Endorsed by the Committee for Practice Guidelines of the European Society of Cardiology. Eur J Prev Cardiol 2014 Jun;21(6):664-681. [doi: 10.1177/2047487312449597] [Medline: 22718797]

3. Frederix I, Van DN, Hansen D, Berger J, Bonne K, Alders T, et al. Increasing the medium-term clinical benefits of hospital-based cardiac rehabilitation by physical activity telemonitoring in coronary artery disease patients. Eur J Prev Cardiol 2015 Feb;22(2):150-158. [doi: 10.1177/2047487313514018] [Medline: 24249840]

4. Janssen V, De GV, van EH, Maes S. Beyond resolutions? A randomized controlled trial of a self-regulation lifestyle programme for post-cardiac rehabilitation patients. Eur J Prev Cardiol 2013 Jun;20(3):431-441. [doi: 10.1177/2047487312441728] [Medline: 22396248]

5. Brubaker PH, Rejeski WJ, Smith MJ, Sevensky KH, Lamb KA, Sotile WM, et al. A home-based maintenance exercise program after center-based cardiac rehabilitation: effects on blood lipids, body composition, and functional capacity. $\mathbf{J}$ Cardiopulm Rehabil 2000;20(1):50-56. [Medline: 10680098] 
6. Lear SA, Spinelli JJ, Linden W, Brozic A, Kiess M, Frohlich JJ, et al. The Extensive Lifestyle Management Intervention (ELMI) after cardiac rehabilitation: a 4-year randomized controlled trial. Am Heart J 2006 Aug;152(2):333-339. [doi: 10.1016/j.ahj.2005.12.023] [Medline: 16875919 ]

7. Avila A, Goetschalckx K, Vanhees L, Cornelissen V. A Randomized Controlled Study Comparing Home-Based Training with Telemonitoring Guidance Versus Center-Based Training in Patients with Coronary Heart Disease: Rationale and Design of the Tele-Rehabilitation in Coronary Heart Disease (TRiCH) Study. J Clin Trials 2014;04(04):1-5. [doi: 10.4172/2167-0870.1000175]

8. Rawstorn JC, Gant N, Direito A, Beckmann C, Maddison R. Telehealth exercise-based cardiac rehabilitation: a systematic review and meta-analysis. Heart 2016 Dec 01;102(15):1183-1192. [doi: 10.1136/heartjnl-2015-308966] [Medline: 26936337]

9. Ferrier S, Blanchard CM, Vallis M, Giacomantonio N. Behavioural interventions to increase the physical activity of cardiac patients: a review. Eur J Cardiovasc Prev Rehabil 2011 Feb;18(1):15-32. [doi: 10.1097/HJR.0b013e32833ace0e] [Medline: 20502341]

10. Buckingham SA, Taylor RS, Jolly K, Zawada A, Dean SG, Cowie A, et al. Home-based versus centre-based cardiac rehabilitation: abridged Cochrane systematic review and meta-analysis. Open Heart 2016;3(2):e000463 [FREE Full text] [doi: 10.1136/openhrt-2016-000463] [Medline: 27738516]

11. Hendel R, Carey K. In: Hendel R, Carey K, editors. Cardiology Procedures: A Clinical Primer. London: Imprint Springer; 2017:A.

12. Garmin International Inc. Garmin Connect. URL: https://connect.garmin.com/nl-NL/[WebCite Cache ID 6xRyfpipN]

13. Kraal JJ, Peek N, Van DAMME, Kemps HM. Effects of home-based training with telemonitoring guidance in low to moderate risk patients entering cardiac rehabilitation: short-term results of the FIT@Home study. Eur J Prev Cardiol 2014 Nov;21(2 Suppl):26-31. [doi: 10.1177/2047487314552606] [Medline: 25354951]

14. Walker H, Hall W, Hurst J. Clinical methods: the history, physical, and laboratory examinations. 3rd ed. Boston: Butterworths; 1990.

15. Pattyn N, Vanhees L, Cornelissen VA, Coeckelberghs E, De MC, Goetschalckx K, et al. The long-term effects of a randomized trial comparing aerobic interval versus continuous training in coronary artery disease patients: 1-year data from the SAINTEX-CAD study. Eur J Prev Cardiol 2016 Dec;23(11):1154-1164. [doi: 10.1177/2047487316631200] [Medline: 26858279]

16. Wallace TM, Matthews DR. The assessment of insulin resistance in man. Diabet Med 2002 Jul;19(7):527-534. [Medline: 12099954]

17. Marques-Vidal P, Mazoyer E, Bongard V, Gourdy P, Ruidavets J, Drouet L, et al. Prevalence of insulin resistance syndrome in southwestern France and its relationship with inflammatory and hemostatic markers. Diabetes Care 2002 Aug;25(8):1371-1377. [Medline: 12145237]

18. Wasserman KH, Sietsema K, Sue D, Stringer W, MD, Whipp B, MD. In: Wasserman KH, editor. Principles of exercise testing and interpretation; including pathophysiology and clinical applications, 5th ed. Portland: Wolters Kluwer Health/Lippincott Williams \& Wilkins, 2012; 2015.

19. Garber CE, Blissmer B, Deschenes MR, Franklin BA, Lamonte MJ, Lee I, et al. American College of Sports Medicine position stand. Quantity and quality of exercise for developing and maintaining cardiorespiratory, musculoskeletal, and neuromotor fitness in apparently healthy adults: guidance for prescribing exercise. Med Sci Sports Exerc 2011 Jul;43(7):1334-1359. [doi: 10.1249/MSS.0b013e318213fefb] [Medline: 21694556]

20. Kavanagh T, Mertens DJ, Hamm LF, Beyene J, Kennedy J, Corey P, et al. Peak oxygen intake and cardiac mortality in women referred for cardiac rehabilitation. Journal of the American College of Cardiology 2003;17;42(12):2139-2143 https://www.sciencedirect.com/science/article/pii/S0735109703013056?via\%3Dihub [FREE Full text] [doi: 10.1016/j.jacc.2003.07.028] [Medline: 14680741$]$

21. Frederix I, Hansen D, Coninx K, Vandervoort P, Vandijck D, Hens N, et al. Medium-Term Effectiveness of a Comprehensive Internet-Based and Patient-Specific Telerehabilitation Program With Text Messaging Support for Cardiac Patients: Randomized Controlled Trial. J Med Internet Res 2015;17(7):e185 [FREE Full text] [doi: 10.2196/jmir.4799] [Medline: 26206311]

22. Widmer RJ, Collins NM, Collins CS, West CP, Lerman LO, Lerman A. Digital health interventions for the prevention of cardiovascular disease: a systematic review and meta-analysis. Mayo Clin Proc 2015 Apr;90(4):469-480. [doi: 10.1016/j.mayocp.2014.12.026] [Medline: 25841251]

23. Huang K, Liu W, He D, Huang B, Xiao D, Peng Y, et al. Telehealth interventions versus center-based cardiac rehabilitation of coronary artery disease: A systematic review and meta-analysis. Eur J Prev Cardiol 2015 Aug;22(8):959-971. [doi: 10.1177/2047487314561168] [Medline: 25488550]

24. Frederix I, Vanhees L, Dendale P, Goetschalckx K. A review of telerehabilitation for cardiac patients. J Telemed Telecare 2015 Jan;21(1):45-53. [doi: 10.1177/1357633X14562732] [Medline: 25475219]

25. Swain DP, Franklin BA. VO(2) reserve and the minimal intensity for improving cardiorespiratory fitness. Med Sci Sports Exerc 2002 Jan;34(1):152-157. [Medline: 11782661]

26. Mezzani A, Hamm LF, Jones AM, McBride PE, Moholdt T, Stone JA, European Association for Cardiovascular PreventionRehabilitation, American Association of CardiovascularPulmonary Rehabilitation, Canadian Association of 
Cardiac Rehabilitation. Aerobic exercise intensity assessment and prescription in cardiac rehabilitation: a joint position statement of the European Association for Cardiovascular Prevention and Rehabilitation, the American Association of Cardiovascular and Pulmonary Rehabilitation and the Canadian Association of Cardiac Rehabilitation. Eur J Prev Cardiol 2013 Jun;20(3):442-467. [doi: 10.1177/2047487312460484] [Medline: 23104970]

27. Ayabe M, Brubaker PH, Dobrosielski D, Miller HS, Kiyonaga A, Shindo M, et al. Target step count for the secondary prevention of cardiovascular disease. Circ J 2008 Feb;72(2):299-303 [FREE Full text] [Medline: 18219170]

28. Kraal JJ, Van DAMME, Abu-Hanna A, Stut W, Peek N, Kemps HM. Clinical and cost-effectiveness of home-based cardiac rehabilitation compared to conventional, centre-based cardiac rehabilitation: Results of the FIT@Home study. Eur J Prev Cardiol 2017 Aug;24(12):1260-1273 [FREE Full text] [doi: 10.1177/2047487317710803] [Medline: 28534417]

29. ter HN, Huisstede BMA, Stam HJ, van DRT, Sunamura M, van DBRJG. Does cardiac rehabilitation after an acute cardiac syndrome lead to changes in physical activity habits? Systematic review. Phys Ther 2015 Feb;95(2):167-179. [doi: 10.2522/ptj.20130509] [Medline: 25278337]

30. Prince SA, Saunders TJ, Gresty K, Reid RD. A comparison of the effectiveness of physical activity and sedentary behaviour interventions in reducing sedentary time in adults: a systematic review and meta-analysis of controlled trials. Obes Rev 2014 Nov;15(11):905-919 [FREE Full text] [doi: 10.1111/obr.12215] [Medline: 25112481]

31. King NA, Caudwell P, Hopkins M, Byrne NM, Colley R, Hills AP, et al. Metabolic and behavioral compensatory responses to exercise interventions: barriers to weight loss. Obesity (Silver Spring) 2007 Jun;15(6):1373-1383 [FREE Full text] [doi: 10.1038/oby.2007.164] [Medline: 17557973 ]

32. de MBP, Marins JCB, Franceschini SDCC, Reis JS, Amorim PRDS. Aerobic exercise did not have compensatory effects on physical activity levels in type 2 diabetes patients. J Sports Sci 2015 Sep;33(6):545-551. [doi: 10.1080/02640414.2014.951875] [Medline: 25259751]

33. Biswas A, Faulkner GE, Oh PI, Alter DA. Patient and practitioner perspectives on reducing sedentary behavior at an exercise-based cardiac rehabilitation program. Disabil Rehabil 2017 Jun 06:1-8. [doi: 10.1080/09638288.2017.1334232] [Medline: 28583032]

34. Clark AM, Hartling L, Vandermeer B, McAlister FA. Meta-analysis: secondary prevention programs for patients with coronary artery disease. Ann Intern Med 2005 Nov 1;143(9):659-672. [Medline: 16263889]

35. Smith KM, Arthur HM, McKelvie RS, Kodis J. Differences in sustainability of exercise and health-related quality of life outcomes following home or hospital-based cardiac rehabilitation. Eur J Cardiovasc Prev Rehabil 2004 Aug;11(4):313-319. [Medline: 15292765]

36. Brito LBBD, Ricardo DR, Araújo DSMSD, Ramos PS, Myers J, Araújo CGSD. Ability to sit and rise from the floor as a predictor of all-cause mortality. Eur J Prev Cardiol 2014 Jul;21(7):892-898. [doi: 10.1177/2047487312471759] [Medline: $\underline{23242910]}$

37. Oerkild B, Frederiksen M, Hansen JF, Simonsen L, Skovgaard LT, Prescott E. Home-based cardiac rehabilitation is as effective as centre-based cardiac rehabilitation among elderly with coronary heart disease: results from a randomised clinical trial. Age Ageing 2011 Jan;40(1):78-85. [doi: 10.1093/ageing/afq122] [Medline: 20846961]

38. Mroszczyk-McDonald A, Savage PD, Ades PA. Handgrip strength in cardiac rehabilitation: normative values, interaction with physical function, and response to training. J Cardiopulm Rehabil Prev 2007;27(5):298-302. [doi: 10.1097/01.HCR.0000291297.70517.9a] [Medline: 17885508]

39. Thomaes T, Thomis M, Onkelinx S, Goetschalckx K, Fagard R, Cornelissen V, et al. Muscular strength and diameter as determinants of aerobic power and aerobic power response to exercise training in CAD patients. Acta cardiologica 2012 Aug;1;67(4):399-406. [doi: 10.2143/AC.67.4.2170680]

40. Sumide T, Shimada K, Ohmura H, Onishi T, Kawakami K, Masaki Y, et al. Relationship between exercise tolerance and muscle strength following cardiac rehabilitation: comparison of patients after cardiac surgery and patients with myocardial infarction. J Cardiol 2009 Oct;54(2):273-281 [FREE Full text] [doi: 10.1016/j.jjcc.2009.05.016] [Medline: 19782265]

41. Servantes DM, Pelcerman A, Salvetti XM, Salles AF, de APF, de SFCA, et al. Effects of home-based exercise training for patients with chronic heart failure and sleep apnoea: a randomized comparison of two different programmes. Clin Rehabil 2012 Jan;26(1):45-57. [doi: 10.1177/0269215511403941] [Medline: 21937519]

42. Conraads VM, Pattyn N, De MC, Beckers PJ, Coeckelberghs E, Cornelissen VA, et al. Aerobic interval training and continuous training equally improve aerobic exercise capacity in patients with coronary artery disease: the SAINTEX-CAD study. Int J Cardiol 2015 Jan 20;179:203-210 [FREE Full text] [doi: 10.1016/j.ijcard.2014.10.155] [Medline: 25464446]

43. Hwang R, Bruning J, Morris N, Mandrusiak A, Russell T. A Systematic Review of the Effects of Telerehabilitation in Patients With Cardiopulmonary Diseases. J Cardiopulm Rehabil Prev 2015;35(6):380-389. [doi: 10.1097/HCR.0000000000000121] [Medline: 26034937]

44. Aamot I, Forbord SH, Gustad K, Løckra V, Stensen A, Berg AT, et al. Home-based versus hospital-based high-intensity interval training in cardiac rehabilitation: a randomized study. Eur J Prev Cardiol 2014 Sep;21(9):1070-1078. [doi: 10.1177/2047487313488299] [Medline: 23613224] 


\author{
Abbreviations \\ CAD: coronary artery disease \\ CHD: coronary heart disease \\ CR: cardiac rehabilitation \\ CVD: cardiovascular diseases \\ HDL: high-density lipoprotein \\ HG: hand grip \\ HOMA: homeostasis assessment \\ HRQoL: health-related quality of life \\ HRR: heart rate reserve \\ LDL: how-density lipoprotein \\ RER: hespiratory exchange ratios \\ SRT: sitting-rising test \\ TRiCH: TeleRehabilitation in Coronary Heart \\ VO $2 \mathbf{P}$ : peak oxygen uptake \\ VT: ventilatory threshold
}

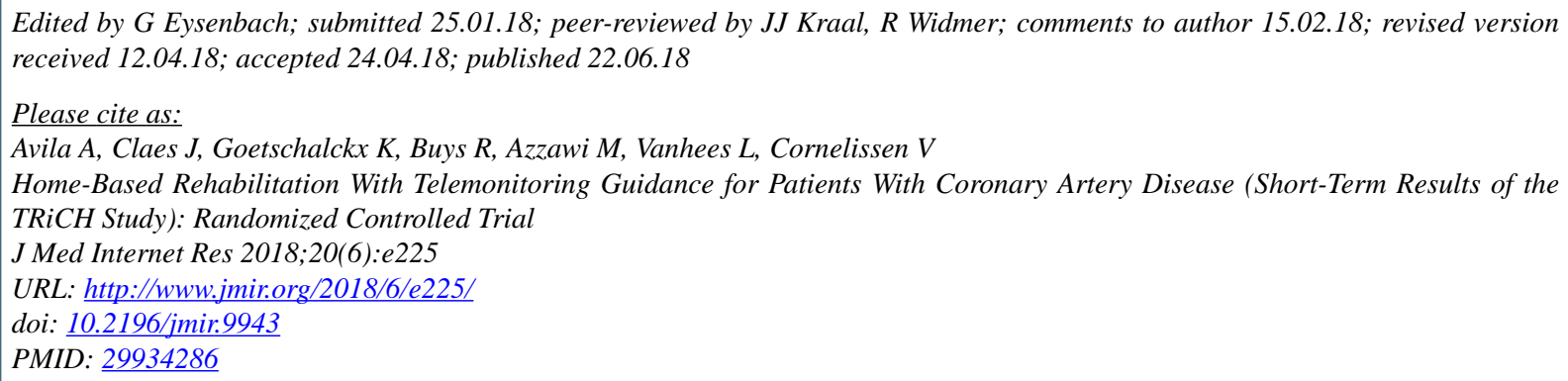

(C)Andrea Avila, Jomme Claes, Kaatje Goetschalckx, Roselien Buys, May Azzawi, Luc Vanhees, Véronique Cornelissen. Originally published in the Journal of Medical Internet Research (http://www.jmir.org), 22.06.2018. This is an open-access article distributed under the terms of the Creative Commons Attribution License (https://creativecommons.org/licenses/by/4.0/), which permits unrestricted use, distribution, and reproduction in any medium, provided the original work, first published in the Journal of Medical Internet Research, is properly cited. The complete bibliographic information, a link to the original publication on http://www.jmir.org/, as well as this copyright and license information must be included. 